ISSN e- 2594-1100

en-claves del pensamiento / núm. 30 / julio-diciembre / 2021 / e473

https://doi.org/10.46530/ecdp.v0i30.473 RESEÑAS

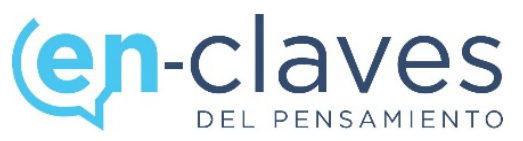

\title{
CAMINOS ÉTICOS Y LITERARIOS: CONJUNCIÓN DE MIRADAS DESDE LAS HUMANIDADES
}

Ethical and Literary Pathways: A Confluence of Perspectives

from the Humanities

Enriqueta Guadalupe del Río Martínez, Tecnológico de Monterrey, México

Correo electrónico: quetadelrio@tec.mx

Rafael Modesto de Gasperín Gasperín, Tecnológico de Monterrey, México Correo electrónico: rgasperi@tec.mx

Recibido: $13 / 06 / 2021$

Aceptado: 17/07/2021

Publicado: 30/07/2021

Cómo citar: del Río Martínez, E., \& de Gasperín Gasperín, R. (2021). Caminos éticos y literarios: conjunción de miradas desde las humanidades. EN-CLAVES del pensamiento, O(30), e473.

doi:https://doi.org/10.46530/ecdp.v0i30.473

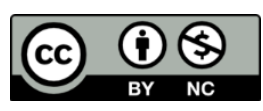

Esta obra está protegida bajo una Licencia

Creative Commons Atribución - No comercial

4.0 Internacional

Margo Echenberg, Osmar Sánchez-Aguilera e Inés Sáenz (Coords.), Humanidades ¿Todavía? Alternativas para pensarnos desde la Literatura y la Ética. México: Porrúa-Tecnológico de Monterrey, 2018, 285 pp.

Humanidades ¿Todavía? Alternativas para pensarnos desde la Literatura y la Ética: el cuestionamiento inscrito en el adverbio del título del libro advierte sobre la batalla que las Humanidades libran en el contexto universitario actual. Esta obra colectiva plantea, desde diversas ópticas y prácticas, que es posible pensar y reflexionar sobre lo humano, sobre nosotros y nuestro devenir mediante el diálogo entre la Ética y la Literatura; es decir, es posible detenernos, abrir espacios para una mirada y una escucha dilatadas ante lo propio y ante lo que nos rodea.

Abre con una revisión del "pulso actual de las Humanidades" desde tres conceptos ineludibles en nuestras relaciones hoy: lo posthumano, la figura del lector-espectador del nuevo contexto literario, y la cultura-mundo. Es decir, se pretende una reconsideración de lo humano y con ello un replanteamiento de las mismas preguntas acorde con los tiempos actuales.

www.enclavesdelpensamiento.mx

https://doi.org/10.46530/ecdp.v0i30.473 
El texto invita a revalorar la educación humanista como la puerta de acceso a una mirada crítica del mundo y como el ejercicio de un quehacer práctico que permita revalorar la experiencia existencial en la búsqueda de sentido. En el espacio de las Humanidades y mediante la "hermandad de las disciplinas de Literatura, Ética y Ciudadanía" se abren intersticios de reflexión a un entorno educativo dominado por el pragmatismo y la educación tecnocientífica.

El alcance de la obra y la pluralidad de sus textos ofrece a los lectores una muestra de las infinitas posibilidades de suscitar en la academia aproximaciones transdisciplinarias que estimulen el pensamiento, propicien la reflexión y amplíen los paradigmas de comprensión de la existencia.

Humanidades ¿Todavía? Alternativas para pensarnos desde la Literatura y la Ética se divide en tres apartados: "Teorías o metodología", compuesto por cuatro artículos que bordan en torno a la Literatura, la Filosofía, la Ética y la Estética como sostén de las Humanidades; "Análisis textuales", constituido por ocho capítulos que ofrecen un conjunto heterogéneo de análisis literario y cuestionamientos éticos, y "Anclaje pedagógico", con dos artículos que brindan la experiencia del aula de sus autores; cierra un epílogo sobre "la conciencia y autoconciencia ética de la literatura". Coordinado por Margo Echenberg, Osmar Sánchez Aguilera e Inés Sáenz, en el libro participaron 14 profesores del Tecnológico de Monterrey.

El ensayo inicial, de Dora Elvira García, pretende probar que "El cultivo de la imaginación literaria [es un] recurso del aprendizaje ético [propicio para la] búsqueda de la paz". La autora plantea la necesidad urgente de recomponer las Humanidades pues hay una falta de correspondencia entre los avances alcanzados en términos tecnocientíficos y las taras observadas en cuanto al desarrollo ético.

Bajo la premisa de que la realización ética requiere de la imaginación, Dora Elvira García aboga por la defensa y el "rescate del mundo de la vida", es decir, de crear formas vivas, concretas que con apoyo del ingenio y con la humildad del cuestionamiento hagan posible un acercamiento al otro, abran espacios a la pluralidad, favorezcan ver desde nuevos horizontes. La autora enuncia el concepto de "crisis silenciosa" de Nussbaum que remite a la necesidad de estar justificando el valor de las Humanidades y reitera que en este "mundo empobrecido de humanismo" es mediante la imaginación que se pueden "visualizar otros escenarios". Precisamente los educadores son quienes pueden "emancipar la inteligencia" y despertar la sensibilidad ética que ayude a suprimir los grandes males de la humanidad: miseria, exclusión, injusticia e inequidad.

La modernidad y la búsqueda del progreso estrecharon las opciones para el hombre, provocando un desequilibrio que alejó a unos de otros y sofocó la imaginación. Finaliza su argumentación con un ejercicio que ejemplifica cómo el teatro sirve para el aprendizaje ético en tanto otorga el poder de "vibrar en conjunción", a decir de Adela Cortina, o de "vivir la vida vista en los otros", según las enseñanzas de Tagore.

Mientras que Dora Elvira García propone que las Humanidades abrigan una esperanza para que el ser humano construya escenarios de paz, Mónica Miroslava Salcido insiste en la recuperación de la filosofía como una práctica incansable, como un ejercicio existencial de búsqueda constante que, como actividad teorética, lleve a una actitud cuestionadora que emancipe al ser humano y le permita pensar por sí mismo. La autora nos anima con el llamado socrático a "la perplejidad y la duda" e invita a acercarse a producciones intelectuales y artísticas con la intención de que esa experiencia estética nos haga capaces de trazar nuestro propio horizonte.

Salcido concibe la filosofía como forma de vida, es decir, como un arte, "el arte de vivir" en tanto "uno no es sino la escritura que hace de sí mismo", de ahí que el título de su artículo señale "la vida como logro literario". Este ejercicio filosófico demanda que "la edificación de la libertad

www.enclavesdelpensamiento.mx

https://doi.org/10.46530/ecdp.v0i30.473 
individual que nos caracteriza debe ir de la mano de la edificación de la responsabilidad social". Por eso, según ella, la filosofía ha de formar parte de los planes de estudio porque permite la conciencia crítica, la sospecha, el pensar ético y el huir de la masificación del pensamiento, mientras da la pauta para hallar - al menos, buscar incansablemente - un horizonte más libre y pleno en el que se ejerza "el arte de vivir".

En "Ética en estado poético: del juego hermenéutico a la práctica ética", Judith Ruiz-Godoy avanza hacia una propuesta más íntima: "un modo de lectura que propicie la práctica del conocimiento de sí, a través de la lectura de poesía". Parte de la distinción entre lo ético como adjetivo y una concepción ética que cuestione y, al hacerlo, disloque la existencia y permita ser conscientes del lugar que ocupamos en la sociedad, de cómo estamos imbuidos en metanarrativas aceptadas como naturales. La autora sostiene la tesis de que "todo cuestionamiento sobre la ética es un ejercicio ético"; y que "la libertad es fundamento de la ética". Apoyada en Gadamer, RuizGodoy entra en el juego hermenéutico que supone el encuentro con la poesía donde se fusionan los horizontes de quien escribe el texto y de quien lo interpreta. Con un poema de Félix Grande ella ejemplifica un método de lectura y el proceso hermenéutico.

Al entrar en ese juego, el mismo lector provoca la reflexión sobre su propia vida pues lee desde su propio horizonte y ejerce la "práctica ética del conocimiento de sí". Este juego entre poesía y filosofía lleva a la comprensión de la ética, pues ambas facultan para comprendernos a nosotros mismos y a los demás. Ruiz-Godoy concluye que "el método de interpretación hermenéutica de la poesía es una práctica ética".

Basada en la idea de que en los estilos de vida contemporáneos las artes han sido relegadas a espacios periféricos o a prácticas elitistas, con la consiguiente pérdida de su comprensión cabal, Lourdes Epstein propone como eje de su propuesta el término "patente cultural", "una noción analógica que apunta a la vinculación de esta experiencia [estética] y beneficios de corte social" sin intención de acreditar propiedad; o sea, la vinculación de bienes intangibles (como el intercambio activo y atento frente al mundo que permite la experiencia estética), con el bienestar, beneficio o ganancia social. Considera que, si es posible fomentar la imaginación, las cosas se verán con la distancia precisa que permita una comprensión libre de prejuicios.

La autora enfatiza la necesidad de las prácticas artísticas como medio de conexión entre los seres humanos, como fortalecimiento de las instituciones democráticas, y, específicamente, atiende a la literatura como el vehículo idóneo para religar la experiencia estética con nuestra capacidad de respuesta al entorno social. Así mismo, Epstein aboga por un capital social subjetivado que constituya "el equipamiento que facilite al agente el acceso y uso de los recursos de las redes sociales" que posibilite para él las interacciones, pero que en este ejercicio se privilegie la imaginación (como en la propuesta de Dora Elvira García) que ha sido desplazada por el énfasis y la confianza desmedida en la razón.

Este capital cultural que es la lectura puede convertirse en un capital social. Pero el entorno en el que ahora vivimos "no quiere cultura sino entretenimiento", y esa elección supone un demérito del intercambio social, de la experiencia estética compartida. De ahí que la metáfora de la patente cultural, dice Epstein, "funge como una forma de resanar la falta de conciencia que acontece en el consumo cultural del entretenimiento de masas. Convertir el tiempo vacío en tiempo de ocio implica que podamos integrar la experiencia del arte como cultivo de nuestra humanidad compartida".

El segundo apartado de Humanidades ¿Todavía? Alternativas para pensarnos desde la Literatura y la Ética introduce diversas experiencias de análisis textual en que sus autores www.enclavesdelpensamiento.mx https://doi.org/10.46530/ecdp.v0i30.473 
entretejen sus narrativas con el orden práctico de la filosofía que conocemos como Ética. Abre esta sección, "Ética y tragedia. De la conciencia de lo irremediable a la convicción de lo posible. El caso de Antígona", de Ana Laura Santamaría, quien explora la tragedia griega y de qué manera la Ética se hace presente en ella. La reconfiguración política de Grecia transforma la cultura de la vergüenza (vinculada al honor heroico) en la cultura de la culpa y esto desencadena una reconfiguración del orden legal que conducirá a un cambio del “"yo' combativo por el 'nosotros' comunitario". Santamaría toma como eje la Antígona, de Sófocles, para explorar de qué manera, en el siglo XXI, "la ética puede nutrirse de las reflexiones de la tragedia griega". Así mismo, contrasta tres obras latinoamericanas que reescriben la Antígona configurándola en nuevos contextos de reflexión ética.

Considerada la tragedia como "un canto de desesperación", la autora afirma que ésta "ordena, armoniza e ilumina", conjuntando lo apolíneo y lo dionisíaco. Lo notable es que en ese "canto" se revela una verdad que, según el punto de vista, será afirmativa - lo que la tragedia muestra es la dignidad humana que enfrenta la experiencia del dolor-; o negativa — en tanto cuestiona la moralidad tradicional y devela el "falso atavío del hombre civilizado"-. Y sea cual sea la perspectiva, ambas dejan ver que el saber expuesto trasciende los elementos intelectuales y volitivos, pues la comprensión refiere al pathos trágico.

Esta exploración conduce a la autora a reflexionar sobre una ética de la convicción que ilumine nuestra precariedad y permita una prefiguración utópica, tal como analiza en las "nuevas" Antígonas: La pasión según Antígona Pérez, de Luis Rafael Sánchez; La ley de Creón, de Olga Harmony; y, Usted está aquí, de Bárbara Colio, obras en las que se expresa la denuncia ante distintos órdenes que impiden la libertad humana y orillan a las personas a la soledad y el sufrimiento. Ana Laura traza un arco entre la tragedia clásica y la actualidad que invita a los lectores a revalorar la fuerza de los mitos.

Eduardo E. Parrilla a lo largo de su estudio "De la Física a la Ética: reflexiones en torno a la temática de En busca de Klingsor de Jorge Volpi", establece que esa novela se articula temáticamente desde el conocimiento, lo que la singulariza en el contexto de la novela hispanoamericana; es notable el entretejido que logra el novelista mexicano a partir de macrooperaciones discursivas propias del discurso científico como son la demostración y la explicación, además de los procedimientos de comunicación habituales. Plantea el contenido científico en el ámbito de la Física, pero también aparecen significados valorativos e ideológicos que llevan a una reflexión ética.

Parrilla desentraña los elementos discursivos de la obra y, al hacerlo, deja ver que la ciencia, la ideología y la moral suelen moverse en una doble manifestación, lo que abona a esa "contradicción raigal que opera en el devenir de la vida humana". De ahí que afirme que "si por algo la existencia es imperfecta y corruptible es porque se debate en una serie de paradojas".

En "Seis vocales en busca de una ética sin acento", Javier Alejandro Camargo Castillo parte de un epígrafe de Pirandello para plantear el cuestionamiento ético que supone para el narrador Alejandro Paniagua la relación con sus propios personajes en cuentos que presentan las experiencias de migrantes desde la dimensión de su humanidad.

Camargo se apoya en las categorías de labor, acción y trabajo de Hannah Arendt ( $L a$ condición humana) y busca resolver cómo opera esa interconexión entre literatura y Ética. La obra E sin acento se convierte en ese "amigo" que lo acompañará en el trayecto. Su pretensión es proponer lo que él llama una "ética sin acento". Por el ejemplo literario que elige, Camargo se ve obligado a replantear cómo el ethos podría no ser sólo una morada externa (complejizada por el

www.enclavesdelpensamiento.mx

https://doi.org/10.46530/ecdp.v0i30.473 
proceso migratorio), sino una morada interior. "El ethos no es sólo la costumbre, sino la decisión de una continuidad temporal a partir de cierta fidelidad a sí mismo". El estudioso concluye con la invitación a un abordaje de la Ética en lo literario que permita descubrir en la pluralidad y respetar en el otro su singularidad, es decir, que la aproximación sea desde una "ética sin acento".

Continúa el análisis textual de obras literarias mexicanas, pero de muy distinta configuración, con el capítulo de Carlos Zermeño, quien reflexiona sobre dos cuentos de Amparo Dávila en que los mecanismos de lo fantástico permiten revelar circunstancias que bajo los parámetros de lo real o lo establecido permanecen reprimidas y que constituyen verdaderos dilemas éticos. En ambos, los personajes femeninos se hallan en soledad, se ven afectados por fuerzas que los mantienen sujetos, en un estado de crisis, de violencia, de la que no logran escapar.

"El huésped" es un cuento que en su contextura plantea esos dos planos de realidad cuyos sistemas de representación se oponen violentamente, la vida cotidiana de la protagonista y sus hijos, siempre solitarios por las ausencias prolongadas del esposo. Mediante el recurso fantástico, Dávila logra cruzar ese umbral que permite poner de manifiesto ante el lector que las estructuras sociales convencionales, en este caso ese matrimonio, son inoperantes, se sustentan en la infelicidad. Aparece ahí el componente ético para que, desde los silencios propios de la literatura fantástica, sea el lector quien reconstruya y cuestione. En "Música concreta", la personificación del terror se da mediante un sapo horrible que no deja dormir a la protagonista. En ambos cuentos, lo fantástico abre una fisura en la cotidianidad y el lector puede acercarse desde otra perspectiva a lo que acontece sin estar sometido a las normas socioculturales. Puede tomar partido ante el hecho monstruoso de las muertes y hasta justificarlas, porque las reglas bajo las que opera ese mundo de representación se lo permiten. Al lector queda dilucidar esos dilemas que constituyen el texto.

En el capítulo "Silenciar al otro, silenciarse a sí mismo: reflexiones éticas en torno al libro La risa y el olvido, de Milán Kundera, y La bestia del corazón, de Herta Müller”, José Manuel Suárez Noriega se propone realizar una "comparación ideológica" entre ambas obras desde algunos supuestos éticos para suscitar en el lector una profundización en ese componente que la literatura encarna y que, a veces, es evidente, otras no tanto. No se trata, dice el autor, de enjuiciar desde ciertas posturas éticas, sino de provocar la reflexión. Tanto Kundera como Müller son escritores del exilio cuyas historias presentan la fragmentación de los personajes, de sus relaciones, sus fluctuaciones entre la racionalidad y el absurdo que no les permiten concretizar un "proyecto de vida felicitante".

Dice Suárez Noriega: "En ambas novelas el olvido es central para delinear lo que los personajes han perdido y, al mismo tiempo, lo que han tratado de recuperar con inminente fracaso". Ambas opciones conducen a una suerte de callejón sin salida: hacia el pasado están "los rostros del país sumergidos en la miseria”, según palabras de Müller, de los que no es posible deshacerse; mientras que en Kundera el recuerdo de la muerte de la amiga permite no olvidar que su suicidio "nació del derrotismo, el miedo y la impotencia ante un futuro irrealizable". Suárez Noriega advierte que su vacío existencial se corresponde con un vacío ético, pues la moralidad del "Partido" sólo permite las relaciones y proyectos inscritos dentro de sus confines.

Con agudeza, Jessica C. Locke propone examinar la crítica ética-social que entreteje Elena Garro en su obra dramática Los perros, donde acusa la violencia de género y la pobreza de un pueblo que, como muchos otros, son el rostro oculto del llamado "milagro mexicano". Locke desentraña en su análisis que no es sólo la marginación del progreso económico lo que trata Garro, sino el fenómeno de la violencia encarnado de manera cíclica en el comportamiento de hombres y mujeres.

www.enclavesdelpensamiento.mx

https://doi.org/10.46530/ecdp.v0i30.473 
Desde la perspectiva ética, Locke sugiere que estos pueblos se manejan bajo una ética utilitarista en tanto hay una preservación de "un sistema que aparentemente funciona", y así es, pero sólo para ciertos grupos de poder. Esta conformación es alimentada por la comunidad misma, pues "las normas sociales son demasiado opresivas y represivas; las tradiciones y supersticiones, demasiado arraigadas, e incluso aceptadas"; y es ese "no lo digas, no lo repitas" lo que hace que tanto hombres como mujeres desde su silencio perpetúen el carácter cíclico de la violencia.

En "De la identificación, la compasión y la distancia", Roberto Domínguez propone que la literatura es un auxiliar de la Ética pues "provee repertorios de acciones humanas y de momentos de decisión" en que podemos sopesar, mediante la propuesta estética y lo que acontece con los personajes, aquello que sugería Wittgenstein sobre la ética en tanto "investigación acerca del significado de la vida o de aquello que hace que la vida merezca vivirse". En resumidas cuentas, la obra literaria permite ejercitar el conocimiento ético de los lectores a través de distintas modalidades: la identificación con el mundo de la obra, la compasión hacia los personajes, y el distanciamiento crítico sobre los eventos propuestos por el autor.

Domínguez Cáceres se apoya en tres autores (Bibiana Camacho, Ruy Feben y Marina Perezagua), desde cuyos cuentos va trabajando estas modalidades. Focaliza el análisis a partir de elementos como la voz narrativa, su relación con el personaje y las acciones de éste. Una nota importante en este proceso de interacción hermenéutico con la obra es que las respuestas a las acciones de los personajes se hallan dentro del mismo texto. Dice Domínguez que el resultado de la lectura, atendiendo a lo ético, es que ésta "sea una clave para que la compasión con el otro, el personaje, promueva otra entre el lector y su mundo cotidiano".

Como si se cerrara un círculo, el último capítulo de esta serie vuelve a lo clásico. Cristina Mondragón realiza un "Análisis temático de textos literarios: el héroe clásico y el medieval". En su capítulo, ella parte de que un acercamiento ético a la obra literaria supone "una lectura abierta a la posibilidad de encuentro con códigos morales más o menos variables", acordes a las circunstancias históricas en que operan, pero cuya "problematización" puede abrir un espacio para las decisiones éticas. Así, propone el análisis del tema heroico para revisar cómo los héroes clásicos y medievales se rigen por códigos de comportamiento ético ante los que nosotros, lectores contemporáneos, podemos ejercer una discusión ética. La autora define la figura del héroe y su constitución arquetípica como modelo de los valores éticos de la sociedad de que emana. Mondragón invita a seguir reflexionando sobre las representaciones actuales de héroes y superhéroes a fin de recuperar para ellos el modelo de virtudes y valores orientados a la humanización que nos conduzca a vidas más plenas.

El apartado titulado "Anclaje pedagógico" abre con el texto "Benedetti como punto de partida de la discusión ética", de María Leticia Flores Palacios, quien expone de qué manera la literatura del uruguayo es terreno fértil para la problematización y el análisis de conceptos de interés ético a partir de esos universos ficcionales en que se cuestiona la felicidad, el sentido del trabajo, la dignidad y el respeto humanos. A partir de esos relatos y ejes llega a conclusiones sobre el reconocimiento del valor del Otro, del valor de la vida misma, de la experiencia como aprendizaje ante nuevas situaciones humanas.

Por su parte, Alberto Navarro, en "Literatura y ética. Una relación crítico-reflexiva", realiza un ejercicio que manifiesta las posibilidades de la literatura para detonar el pensamiento crítico, suscitar la reflexión y provocar la práctica de la escritura en torno a contenidos éticos. El autor trabaja conceptos del curso Ética, persona y sociedad a la luz de la obra El pueblo que no quería crecer, de Ikram Antaki y, mediante intertextos escritos por estudiantes, muestra cómo ese vínculo 
favorece la adquisición del conocimiento y reflexión ética, política, ciudadana. Navarro explica que el manejo de la literatura como recurso espejo la sitúa como un espacio "desde el cual podemos habitar con nuestro pensamiento, emociones, sensaciones, interrogantes, memorias". Esa morada abre infinitos caminos a nuestra existencia.

En el epílogo, "Conciencia y autoconciencia ética de la literatura”, Osmar Sánchez Aguilera, glosando a César Vallejo, concluye que "el artista es, inevitablemente, un sujeto ético; esto es, un sujeto con mucha conciencia de su ser en el mundo y de su estar con sus semejantes. Ni mejor ni peor que los otros por eso: sólo muy consciente, tal vez más consciente. Y decir conciencia... equivale a decir, también, autoconciencia". Para respaldar esa observación se ocupa de un poema - del propio Vallejo - en el que termina cuestionándose la sostenibilidad moral de la poesía (y por extensión, de la literatura) en un mundo que no puede modificar del todo. El poema que comienza su recorrido documentando que "Un hombre pasa con un pan al hombro", cierra preguntándose “¿Cómo hablar del no-yo sin dar un grito?”, un acto tan irracional, tan instintivo, tan ajeno a la poesía.

Así, Sánchez Aguilera concluye con un cuestionamiento de la literatura orientado hacia la propia literatura "en virtud de la precariedad moral de su ejercicio o praxis, por cuanto ella no se muestra con capacidad de contribuir, desde su propio fuero, a modificar el mundo realmente existente". Desde luego, eso no hace sino iluminar la amplitud del territorio abarcable por la conciencia ética de la literatura, trátese del entorno, de lectores, de versos, de piezas teatrales, de cuentos, de novelas, de ensayos o de autores.

Humanidades ¿Todavía? Alternativas para pensarnos desde la Literatura y la Ética confirma que la intersubjetividad y la interdisciplinariedad se tornan cada día más importantes en las reflexiones del orden práctico al que conocemos como Ética, por ello la literatura — desde sus formas y sus contenidos - se convierte en un maravilloso dispositivo en cuanto se apropia del lenguaje para que el pensamiento sea capaz de escuchar las narrativas de otros y la posibilidad de aproximarnos a ellos, y a nosotros mismos. El hecho de que un colectivo del Tecnológico de Monterrey confluya en este proyecto editorial permite constatar cuánta energía conservan las Humanidades aun en entornos universitarios regidos en apariencia por aires contrarios. Los planteamientos teóricos que arropan a las Humanidades dejan entrever los vasos comunicantes entre las disciplinas del área, a la par que conducen al replanteamiento crítico del ser humano ante sí. La interdisciplinariedad se advierte tanto en la polífonía de estudios que incorporan el interés por la antigüedad clásica, la perspectiva de género, lo fantástico como caminos alternos, lo cientifista, así como también en la variedad de géneros discursivos abordados. Ante el cuestionamiento implícito en el título del libro: Humanidades ¿Todavía?, el texto mismo parece responder: no sólo todavía, sino siempre.

Enriqueta Guadalupe del Río Martínez Rafael Modesto de Gasperín Gasperín

www.enclavesdelpensamiento.mx https://doi.org/10.46530/ecdp.v0i30.473 